\title{
Da educação I.0 à educação 3.0: desafios para a prática docente no Século XXI
}

\author{
From education I.0 to education 3.0: challenges for teaching practice \\ in the 2 I st Century
}

\section{De la educación I.0 a la educación 3.0: retos para la enseñanza de la práctica en el Siglo XXI}

\author{
Adriana Alves Novais Souza 1 \\ https://orcid.org/0000-0002-8889-8809 \\ Henrique Nou Schneider ${ }^{2}$ \\ https://orcid.org/0000-0003-2354-576X
}

\begin{abstract}
Resumo: Este artigo tem por objetivo analisar as percepções de estudantes da graduação acerca do uso de plataformas online como ambiente colaborativo de aprendizagem e sua relevância para os processos formativos em moldes da Educação 3.0. Trata-se de um recorte de uma dissertação de mestrado em Educação na área de tecnologia e educação, que teve como prática de pesquisa $\circ$ uso de redes sociais como ambiente de aprendizagem, desenvolvida na disciplina Português Instrumental, do curso de graduação em Letras Vernáculas de uma universidade federal. A pesquisa, de abordagem qualitativa, teve por sujeitos os dezessete estudantes da disciplina e foi realizada através do método da Pesquisa-formação, utilizando como instrumentos de coleta de dados a observação participante, o questionário e a entrevista semiestruturada, esta última realizada apenas com os alunos licenciandos da turma. Os dados evidenciaram a necessidade de se refletir sobre as práticas necessárias à docência na atualidade, destacando, com base nos depoimentos dos participantes, a ausência na formação inicial de atividades e práticas mais dinâmicas, em que haja uso efetivo das tecnologias, o que culmina em insegurança em relação aos desafios futuros. Se o estudante está em processo de formação, independentemente dos destinos profissionais escolhidos, é preciso atrelar $o$ ensino às práticas que se fazem na sociedade informatizada e interconectada em que vivemos.
\end{abstract}

Palavras-chave: Educação 3.0. Tecnologias Digitais de Informação e Comunicação. Formação docente.

Abstract:This article aims to analyze the perceptions of undergraduate students about the use of online platforms as a collaborative learning environment and its relevance to the formative processes in the molds of Education 3.0. This is an excerpt from a Master's thesis in Education in the area of technology and education, which had as its research practice the use of social networks as a learning environment, developed in the Portuguese Instrumental discipline, of the undergraduate course in Vernacular Letters of a federal university. The

\footnotetext{
' Doutoranda em Educação na Universidade Federal de Sergipe. Professora da Secretaria de Educação de Sergipe. E-mail: dria.novais.souza@gmail.com

${ }^{2}$ Doutor em Engenharia de Produção pela Universidade Federal de Santa Catarina. Professor da Universidade Federal de Sergipe e do Instituto Federal de Educação, Ciência e Tecnologia de Sergipe. E-mail: hns@terra.com.br
} 
research, with a qualitative approach, had as subjects the seventeen students of the discipline and was carried out through the Research-formation method, using participant observation, the questionnaire and the semistructured interview as instruments of data collection, the latter carried out only with graduating students in the class. The data showed the need to reflect on the practices necessary for teaching today, highlighting, based on the testimonies of the participants, the absence in the initial formation of more dynamic activities and practices, in which there is effective use of technologies, which culminates in insecurity about future challenges. If the student is in the process of training, regardless of the chosen professional destinations, it is necessary to link teaching to the practices that take place in the computerized and interconnected society in which we live.

Keywords: Education 3.0. Digital Information and Communication Technologies. Teacher training.

Resumen: Este artículo tiene como objetivo analizar las percepciones de los estudiantes de pregrado sobre el uso de las plataformas en línea como en torno de aprendizaje colaborativo y su relevancia para los procesos formativos en el marco de la Educación 3.0. Este es un extracto de una tesis de maestría en Educación en el área de tecnología y educación, que tuvo como práctica investigadora el uso de las redes sociales como ambiente de aprendizaje, desarrollado en la disciplina Instrumental Portuguesa, del curso de pregrado en Letras Vernáculas de una universidad federal. La investigación, con un enfoque cualitativo, tuvo como sujetos a los diecisiete estudiantes de la disciplina y se llevó a cabo a través del método Investigación-formación, utilizando la observación participante, el cuestionario y la entrevista semiestructurada como instrumentos de recolección de datos, esta última realizada solamente con los estudiantes graduados de la clase. Los datos evidenciaron la necesidad de reflexionar sobre las prácticas necesarias para la docencia en la actualidad, destacando, a partir de los testimonios de los participantes, la ausencia en la formación inicial de actividades y prácticas más dinámicas, en las cuales exista un uso efectivo de las tecnologías, que culmina en la inseguridad en relación con los desafíos futuros. Si el alumno se encuentra en proceso de formación, independientemente de los destinos profesionales elegidos, es necesario vincular la docencia a las prácticas que se desarrollan en la sociedad informatizada e interconectada en la que vivimos.

Palabras-clave: Educación 3.0. Tecnologías de la información y la comunicación digitales. Formación de profesores.

\section{Introdução}

Na perspectiva de educação como segmento social fundamental para formação do indivíduo em suas interações com o outro e com a própria vivência em sociedade, pretende-se discutir as relações entre educação e processos tecnológicos a partir de uma concepção pertinente no sentido de justificar a necessidade de adequação e mudança nos processos educacionais para o século XXI.

Inicialmente, é preciso compreender que todas as transformações oportunizadas pelas Tecnologias Digitais de Informação e Comunicação (TDIC) nos processos comunicacionais e sociais dos indivíduos evidentemente provocaram mudanças nos perfis dos jovens estudantes das gerações mais atuais. Enquanto estudantes de gerações anteriores eram mais passivos, reservados e silenciosos, os estudantes de hoje são ativos, barulhentos e públicos (FAVA, 20I I), características que suscitaram diferenciações entre as gerações anteriores e a atual, denominando de geração internet (TAPSCOTT, 20I0) ou nativos digitais (PRENSKY, 200I) aos nascidos na era do computador e acesso à internet.

Este artigo tem por objetivo analisar as percepções de estudantes da graduação acerca do uso de plataformas online como ambiente colaborativo de aprendizagem e de sua relevância para os processos formativos em moldes da Educação 3.0. Trata-se de um recorte dos dados coletados em 
uma pesquisa de dissertação ${ }^{3}$ de mestrado em Educação que trata do uso de uma rede social, o Facebook, como ambiente de aprendizagem e que buscou analisar as percepções dos participantes da pesquisa acerca da prática desenvolvida aos moldes da Educação 3.0 (SOUZA, 2015).

Aqui envidou-se provocar reflexões acerca de conceitos como o de geração e nativos digitais, estabelecendo um paralelo entre as formações educacionais em três eras distintas, com características bem marcadas e que, por sua vez, demonstram o quanto a educação atual precisa repensar seus processos e encaminhamentos rumo a uma proposta 3.0, nos moldes apontados por Jim Lengel (20I2), que tem por foco o desenvolvimento de uma pedagogia participativa entre docentes e discentes a partir de uma nova metodologia que prepare o estudante para a dinâmica de mundo no qual está inserido, dinâmica que não possui uma forma definida, mas que muda constantemente.

O aporte teórico está fundamentado, principalmente, nas pesquisas de Allan (2014), Fava (20II), Libâneo (20II), Santos e Blázquez (2005), dentre outros. Compreendemos, a partir desses autores e também mediante os resultados obtidos, que o processo de aprendizagem não se limita ao domínio formal do conhecimento; é preciso lançar mãos do que e como fazer, considerando a abundância de recursos e informações disponíveis na web, presentes em todas as áreas da vida e que podem ocorrer a partir das conexões entre informações, conceitos e saberes.

Neste trabalho, explicitamos o conceito de Educação 3.0 e sua compatibilidade com a geração midiática, multitarefa e de comunicação contínua e em rede; em seguida, apontamos os desafios para a implantação de uma pedagogia baseada nessa perspectiva, trazendo um diálogo com Libâneo (20I I) e, por fim, trazemos os dados empíricos da pesquisa de mestrado que originou este artigo, oriundos de uma prática desenvolvida com alunos da graduação e que explorou as perspectivas do discentes da licenciatura, os quais evidenciam em seus depoimentos os anseios por uma formação cuja base metodológica explore as TDIC, para que a experiência obtida nessa fase seja capaz de prepará-los eficazmente para o exercício da prática, compreendendo-se que as dificuldades precisam ser enfrentadas na formação inicial, para que se estabeleçam estratégias e reflexões sobre ações futuras e assim se evite a sensação de inaptidão para prosseguir na profissão com qualidade.

\section{O que vem a ser Educação 3.0?}

Pensando nas características singulares dos estudantes das gerações atuais, mais ativos, barulhentos e públicos (FAVA, 20I I), é que o professor da Universidade Nova York, Jim G. Lengel, um defensor do conceito de Educação 3.0, discute, dentre outros aspectos, a necessidade de lidar com

\footnotetext{
${ }^{3}$ A dissertação intitulada: $O$ Facebook como ambiente de aprendizagem: uma análise da práxis presencial mediada pelo conectivismo pedagógico (SOUZA, 2015).
} 
os estudantes de uma outra maneira, num processo de gerenciamento e não de monitoramento. Ainda, que é imperativo repensar as práticas de ensino e aprendizagem a fim de estabelecer uma relação entre a forma como ocorre a produção do conhecimento na escola e fora dela, também já discutidos na subseção anterior, porém sob a perspectiva de outros autores.

Apesar de Lengel ter disseminado o termo Educação 3.0, ele foi utilizado pela primeira pelo professor Derek Keats, da Universidade de Witwatersrand, de Johanesburgo, na África do Sul, em 2007 (ALLAN, 20I4), para definir os usos das tecnologias na aprendizagem partindo da necessidade de uma lógica colaborativa em consonância com o formato de sociedade que se tem atualmente, destacando a necessidade de repensar os modelos pedagógicos baseados na figura central do professor como detentor do saber.

Segundo Lengel (20I2), para compreender as tensões e divergências na educação da atualidade, é preciso retroceder no tempo e refletir sobre como educação e trabalho sempre estiveram intrinsecamente relacionados na vida do indivíduo. Para isso, ele estabelece três períodos históricos para a educação: a Educação I.0, a Educação 2.0 e a Educação 3.0. Somente será possível compreender a emergência da Educação 3.0 a partir da contextualização das fases anteriores.

A primeira fase, da Educação e do Trabalho 1.0 foi assim denominada por possuir características mais simples, tipicamente agrárias: as pessoas trabalhavam com a terra, ao ar livre, utilizavam ferramentas simples, de confecção própria, que eles sabiam consertar quando quebravam. As comunidades eram formadas por pessoas que se conheciam e realizavam muitas tarefas em conjunto. Durante o trabalho, era comum jovens e velhos desenvolver atividades juntos e era ainda mais natural que eles conversassem entre si, trocassem experiências e discutissem fatos dos cotidianos enquanto realizavam suas tarefas (LENGEL, 2012). O ofício era passado de pai para filho ou de mestre para aprendiz e o aprendizado adquirido era suficiente para toda a sua carreira.

Analisando a educação desse período, é possível perceber os mesmos moldes do ambiente de trabalho: o aprendizado ocorria em ambiente familiar, na casa do aluno ou do professor ou até mesmo ao ar livre, em grupos pequenos de estudantes, os materiais e recursos didáticos utilizados eram simples, elaborados pelo professor, os filhos geralmente frequentavam as mesmas escolas que seus pais e aprendiam as mesmas coisas. Assim, os ambientes da escola e do trabalho na fase 1.0 eram correspondentes e suas relações seguiam a mesma estrutura simples com as quais os indivíduos estavam familiarizados. A educação desenvolvia competências no aluno de acordo com as necessidades sociais, com predominância nas interações, um valioso legado que "mostra tanto a essência que as instituições de ensino devem manter, quanto aponta a direção do processo de mudança educacional e social que levará à Educação 3.0" (FAVA, 20II, p. 27). Ressalta-se que as tecnologias existentes nessa fase são ferramentas simples e exclusivas para o desenvolvimento de tarefas, confeccionadas (e 
consertadas) pelos próprios usuários e não eram utilizadas para a comunicação, como nas fases seguintes.

A geração posterior, da Educação e do Trabalho 2.0, sofre uma brusca mudança a partir da Revolução Industrial, que vem fragmentar as relações de trabalho humano, tornando-as fabris e mecânicas, exigindo o máximo de produção dos indivíduos e, consequentemente, sua massificação. Impedido de conversar no ambiente de trabalho (mesmo como parte de um grande grupo), o novo perfil de trabalhador conhece a figura do chefe, figura mantenedora da ordem e da disciplina e à qual se deve sempre respeitar para evitar punições. O reflexo dessa mudança de paradigma no trabalho é logo percebido no processo de educação, que passa a ser de cunho preparatório desse indivíduo: as salas passam a contar com um maior número de alunos, sentados enfileirados (para evitar conversas) e que realizam as mesmas tarefas; há ausência de trabalhos em grupo e exige-se silêncio, obediência e respeito à figura do professor, dentre outras características. Em suma, a formação do indivíduo está baseada no modelo industrial. Esse é o cenário da Educação 2.0.

O trabalho na sociedade industrial surgiu como uma violência capaz de reduzir o ser humano a um operário sem autonomia, sem personalidade, um mero submisso em troca de seu salário. Nesse viés, surgem as primeiras críticas sobre a educação nesses moldes, assim como uma linguagem típica a ela relacionada, tais como alienação e anomia, como também a exigência de parâmetros que a caracterizem pela autonomia, liberdade, respeito e colaboração entre seus integrantes.

Nessa fase da Educação e do Trabalho 2.0 evoluem os meios de transporte e comunicação: o telefone, o rádio e a televisão, tecnologias que vêm favorecer a comunicação, a divulgação de informações e encurtar as distâncias, mas que, em contrapartida, possuem características assinaladas por Santaella (2003, p. 52-53) como "[...] produzida por poucos e consumida por uma massa que não tem poder para interferir nos produtos simbólicos que consome [...]". A distinção feita por Santaella reforça ainda mais o caráter massificante desse período.

Aportando na atualidade, verifica-se que as relações de trabalho assumiram características diferenciadas da fase industrial: os ambientes de trabalho estão cada vez mais reduzindo seus grupos, muitos primam pela formação de equipes que se mostrem capazes de resolver problemas através da prática de seus conhecimentos e habilidades, que utilizem intensivamente as tecnologias digitais (muitos profissionais já realizam suas funções de casa, a partir de computadores pessoais), que estejam adaptados à realização de multitarefas e que possuam capacidade de interagir com outras pessoas, inclusive de áreas diversas de sua atuação, através de redes de compartilhamento. Todas essas características determinam o Ambiente de Trabalho 3.0.

Nas fases anteriores, I.0 e 2.0, foi possível reconhecer características comuns entre o ambiente de trabalho e a escola em cada uma delas. Porém, isso não é possível em relação ao ambiente de 
trabalho 3.0. Na educação atual predomina o modelo da Educação 2.0, basta lembrar que as carteiras das salas de aula continuam enfileiradas, apesar dos esforços de muitos educadores de refutar essa organização nos espaços escolares ou verificar como as tarefas ainda são realizadas na maioria das salas de aula: os alunos fazem tarefas iguais, em tempos iguais, independentemente de suas diferenças nos processos cognitivos.

Para Fava (20lI), uma educação nesses moldes tem por foco o desenvolvimento de uma pedagogia participativa entre docentes e discentes a partir de uma nova metodologia que prepare o estudante para a dinâmica de mundo no qual está inserido, dinâmica que não possui uma forma definida, mas que muda constantemente. Trata-se de preparar o aluno para um futuro desconhecido, "no qual eles sobreviverão não pelo que sabem, mas pelas suas habilidades e competências para a busca e aplicação da informação e para a adaptabilidade a um ambiente em constante mutação" (FAVA, 20I I, p. 16).

Dialoga-se com o autor quando ele afirma que metodologias de ensino deverão trabalhar com princípios como o da virtualidade, onde as relações com as pessoas e com a aprendizagem ultrapassem as fronteiras do tempo e do espaço, onde as metodologias sejam producentes em relação às novas exigências de autonomia, flexibilidade, aprendizagem e criatividade das novas e futuras gerações.

Não apenas a educação foi estruturada em gerações, mas no próprio percurso da História percebem-se mudanças relacionadas aos eventos sociais no perfil das crianças de sua geração. É evidente que uma criança que nasce nos dias atuais possui mais facilidade em lidar com as tecnologias digitais, pois é uma "nativa" da sociedade informacional, ao contrário dos nascidos em gerações anteriores, que tiveram que se adaptar ao uso.

Os termos "nativos digitais" e "imigrantes digitais" foi lançado por Prensky, em 200I, apontando a distância comportamental entre as gerações, destacando principalmente a natureza adaptável dos jovens que cresceram com as tecnologias em relação àqueles que entram em contato com o mundo digital numa fase posterior de sua existência, demostrando menor afinidade com a tecnologia.

Apesar da afinidade e desenvoltura de muitos jovens considerados nativos digitais com as tecnologias de última geração, isso não quer dizer que eles possuam criticidade e que suas proposições sejam criativas, pois muitas de suas colocações são fruto do senso comum. Por isso, a mediação de adultos e do professor (no caso da escola) se fazem necessárias, exercendo o papel de orientadores das discussões, encaminhando e incentivando reflexões mais amadurecidas, propondo novas leituras que embasem as discussões e provoquem reflexões aprofundadas sobre os contextos apresentados, sobre os recursos e sobre a própria mídia. Isso requer que o professor também esteja preparado para 
tais interferências, possuindo a formação necessária dentro de uma perspectiva que alie o uso da tecnologia pedagogicamente.

Dentro da concepção que retrata a Educação 3.0, o aluno da atualidade possui um estilo de aprendizagem diferente, pois percebe o mundo com outro olhar, está exposto a uma gama de estímulos visuais e, portanto, a forma como se dá seu processamento de informações e conhecimentos também é diferenciado. As TDIC já fazem parte de sua vida, mas, na escola, nem sempre ele encontra oportunidades de explorá-las, sendo, muitas vezes, proibido o seu uso.

Segundo Allan (20|4), a Educação 3.0 é uma urgência da geração midiática, que exige uma escola em consonância com suas práticas de vida, acostumada a realizar multitarefas, cuja comunicação é contínua e em rede, pois já nasceram digitais, ao contrário dos imigrantes de outras gerações, acostumados a realizar uma coisa de cada vez, de modo seriado (FAVA, 20II). Isso tem provocado incertezas entre os docentes, pois muitos se frustram em não conseguir ensinar ou estimular o alunado em uma época de convergência, de cultura participativa.

Lengel (20I2) defende que, desde que empregada a partir de um planejamento coerente, a tecnologia digital é capaz de mobilizar as atividades em sala de aula, deixando-as mais instigantes e ricas.

A escola que sonhamos é aquela que assegura a todos a formação cultural e científica para a vida pessoal, profissional e cidadã, possibilitando uma relação autônoma, crítica e construtiva com a cultura em suas várias manifestações: a cultura provida pela ciência, pela técnica, pela estética, pela ética, bem como pela cultura paralela [...] para formar cidadãos participantes em todas as instâncias da vida social contemporânea, - que implica articular os objetivos convencionais da escola [...] às exigências postas pela sociedade comunicacional, informática e globalizada: maior competência reflexiva, interação crítica com as mídias e multimídias, conjunção da escola com outros universos culturais, conhecimento e uso da informática, dentre outros (LIBÂNEO, 20II, p. 9-10).

É importante reiterar que professores são oriundos de gerações diferentes e são fruto de suas vivências e experiências ao longo de sua jornada escolar e acadêmica, por isso é fundamental compreender que, como sujeitos de seu tempo e da formação que recebeu, é comum que suas ações possam parecer deslocadas diante de alunos da geração atual, que aprende de forma diferente, pois seus corpos possuem subjetividades que diferem das gerações anteriores; eles partem da imagem e do som para então chegar ao texto. É um grande desafio, aponta Fava (20II), exigir de jovens com intervalos tão curtos de atenção, que consigam sentar e ler um livro por horas.

Não é fácil mudar questões culturais e compreender esse limite é o ponto fundamental para uma mudança de paradigma e para a implementação de um ensino baseado na perspectiva da Educação 3.0. Porém, é importante que o alunado atual encontre na escola estímulos condizentes com suas subjetividades e modos de compreensão; caso contrário, estaremos perpetuando uma geração de 
professores que temem o uso da tecnologia em sala por não compreender seus usos pedagógicos; afinal, os alunos hoje sentados nas carteiras escolares serão os professores das próximas gerações.

$\mathrm{Na}$ Educação 3.0, afirma Lengel (2012), as escolas estão em contexto com o mundo atual, acompanhando suas mudanças e inserindo-as no processo de ensino e aprendizagem e nas relações entre professor e aluno e aluno e aluno. Consiste na criação de uma prática pautada na conectividade e colaboração, a partir do uso de ferramentas digitais que permitam a construção do conhecimento todos-todos, tirando partido da gama de opções à disposição na atualidade, tais como as promovidas pela web 2.0 e, principalmente, pelas redes sociais. A sala de aula, na perspectiva do autor, pode ser qualquer ambiente onde é possível estar conectado, criar e buscar soluções para os problemas. A necessidade de mudança metodológica e o rompimento com uma educação ultrapassada são os principais desafios para uma sólida implementação da Educação 3.0.S

\section{Os desafios da prática pedagógica para a Educação 3.0}

Diante do descompasso entre a educação e o ambiente de trabalho 3.0, das discussões feitas acerca do espaço escolar e da perda de sua referência para o alunado da geração atual, como também da necessidade de novos parâmetros pedagógicos que direcionem uma prática docente voltada para o uso das TDIC como suporte à aprendizagem, é importante discutir os desafios da prática pedagógica guiada pelos pressupostos da Educação 3.0.

[...] por mais que a escola básica seja afetada nas suas funções, na sua estrutura organizacional, nos seus conteúdos e métodos, ela mantém-se como instituição necessária à democratização da sociedade. Por isso, o tema de formação de professores assume no Brasil de hoje importância crucial (LIBÂNEO, 20II, p. 9).

Para Libâneo (20II), um professor didático é aquele que ajuda o aluno a estabelecer uma relação cognitiva e afetiva com a matéria, assegurando as boas condições da busca pelo conhecimento. Dessa forma, a didática se relaciona com os saberes em situações contextualizadas, nas quais os alunos, orientados pelo professor nas suas atividades autônomas, desenvolvem-se a partir de mudanças no modo de ser, agir e pensar

Em 1997, Stahl, citando Sculley (1989), já compreendia o indivíduo como um nó de uma rede que se estendia pelo mundo, provocando mudanças nas formas de socialização e de valores globais, graças às redes de telecomunicações, formando assim as comunidades eletrônicas e construindo um novo contexto para a educação. Os impactos da informação e da tecnologia na educação desencadeiam processos que vão assumindo, conforme a autora, formas relevantes no processo de aprendizagem para a educação 3.0, a saber: I. Disponibilidade de informação; 2. Novas estratégias de pesquisa; 3. 
Aprendizagem sobre tecnologia integrada ao currículo; 4. Desenvolvimento de novas habilidades cognitivas; 5 . metacognição e coaprendizagem.

Ao refletir sobre o uso que a educação pode fazer das TDIC, o professor estará oferecendo aos alunos as experiências educacionais que serão necessárias para seu exercício na sociedade moderna, preparando-os para os papéis que lhes serão exigidos. Stahl (1997) reflete sobre o papel docente nessa perspectiva, considerando quatro aspectos fundamentais: a flexibilidade do currículo (principalmente na formação inicial) numa percepção clara do contexto sócio-político-econômico; a busca constante por auto aperfeiçoamento; a preocupação com a teoria; a prática e a visão do docente como agente de mudança.

Isso porque a tecnologia somente terá impacto nas escolas quando a preparação de bons professores for prioridade, pois "não há reforma educacional, não há proposta pedagógica sem professores, já que são os profissionais mais diretamente envolvidos com os processos e resultados da aprendizagem" (LIBÂNEO, 20II, p. 9). Sendo assim, não há porque exigir do profissional uma mudança de postura em sua prática pedagógica e oferecer-lhe formação em moldes tradicionais, é preciso formá-lo da mesma maneira que se espera que atue.

Embora o professor precise ser preparado a usar adequadamente as novas tecnologias a partir de meios não convencionais, afirma Stahl (1997), esta prática ainda está longe de ser consolidada nos cursos de formação de professores. Além disso, oportunidades de atualização nem sempre são as mais adequadas à sua realidade e necessidade.

A aquisição de conhecimentos por parte do professor é um processo complexo, adaptativo e experiencial [...]. E quanto maior a sua capacidade de adaptação mais facilmente ela será posta em prática em sala de aula ou na escola e será incorporada às práticas profissionais habituais. Um dos objetivos de toda formação válida deve ser o de poder ser experimentada e também proporcionar a oportunidade para desenvolver uma prática reflexiva competente (IMBERNÓN, 2006, p. 17).

Refletir sobre a prática docente e sobre as mudanças no perfil do aluno da geração atual são passos fundamentais para uma ação que possa questionar a validade daquilo que se ensina para o alcance dos objetivos primordiais da educação: o processo de ensino motiva a aprendizagem do aluno? Esse aluno frequenta e participa das aulas, realiza tarefas, estuda para as avaliações por sua própria vontade ou considera-as uma obrigação? Fava (20II) elenca tais questões para que o professor enxergue mais claramente como se dá o processo de aprendizagem para o aluno. Se tal processo se mostra difícil, é um sinal da necessidade de mudança, o que não vai ocorrer apenas por meio das tecnologias, mas pela revisão da metodologia e da prática docente.

Libâneo (20II) apresenta algumas concepções, expostas no Quadro I, que dizem respeito às atitudes docentes a serem adotadas nessa perspectiva: 
Quadro I: Novos paradigmas docentes para a Educação 3.0

\begin{tabular}{|c|c|c|c|c|}
\hline $\begin{array}{c}\text { Ensino como } \\
\text { mediação }\end{array}$ & $\begin{array}{c}\text { Estratégias de } \\
\text { ensinar e aprender }\end{array}$ & Novos paradigmas & Perspectiva crítica & $\begin{array}{c}\text { Docência e Novas } \\
\text { tecnologias }\end{array}$ \\
\hline Aluno como agente & Aprender a pensar & $\begin{array}{c}\text { Escola e prática } \\
\text { interdisciplinares }\end{array}$ & $\begin{array}{c}\text { Apreensão da } \\
\text { realidade pelo } \\
\text { aluno }\end{array}$ & $\begin{array}{c}\text { Desenvolvimento } \\
\text { da capacidade } \\
\text { comunicativa }\end{array}$ \\
\hline $\begin{array}{c}\text { Ajuda pedagógica } \\
\text { docente }\end{array}$ & $\begin{array}{c}\text { Aprender a } \\
\text { aprender }\end{array}$ & $\begin{array}{c}\text { Substituição da } \\
\text { visão } \\
\text { pluridisciplinar } \\
\text { escolares sob uma } \\
\text { visão crítico- } \\
\text { reflexiva }\end{array}$ & $\begin{array}{c}\text { Diversidade } \\
\text { cultural e } \\
\text { contextual }\end{array}$ \\
$\begin{array}{c}\text { Orientação quanto } \\
\text { à ética, valores e } \\
\text { atitudes em relação } \\
\text { à vida }\end{array}$ & Dimensão afetiva & - & - & $\begin{array}{c}\text { Atualização } \\
\text { científica, técnica e } \\
\text { cultural }\end{array}$ \\
\hline
\end{tabular}

Fonte: Organizado pela pesquisadora com base em Libâneo (20I I, p. 30 a 45).

Embora Libâneo não fale em Educação 3.0, sua abordagem compreende princípios para o uso das tecnologias em uma prática que dialoga com elas numa perspectiva totalmente engajada com o que propõem Lengel (20I2) e Fava (20II). Libâneo (20II) ainda destaca que não basta ver as tecnologias digitais fazendo parte do conjunto das mediações culturais característicos do ensino, pois elas são portadoras de ideias, de atitudes, emoções, habilidade, traduzidas em objetivos, métodos e conteúdos de ensino. A inserção eficaz dos meios de comunicação na prática pedagógica pressupõe objetivos de formação humana e deve estar conectada às diversas disciplinas do currículo, intencionalmente e não de forma isolada; sua utilização precisa implicar nas competências e atitudes profissionais docentes, além de, naturalmente, configurar como meios tecnológicos de comunicação humana.

\section{Prática 3.0: o que dizem os estudantes - e futuros docentes - sobre ela?}

A aprendizagem que se faz em rede, que tem por base a concepção sócio-histórica de Vygostky (2008), tem por princípio as relações entre as pessoas. Por isso, "tecnologias precisam ser fontes de aproximação e integração entre os sujeitos aprendentes" (NUNES; NUNES, 2012, p. 127) e, ainda além, elas precisam ser fontes de aproximação entre o conhecimento formal e informal, entre ambientes entre paredes e entre bits, entre o que pode ser apreendido na escola e fora dela. Isso porque a apropriação de metodologias para a aprendizagem em rede não reside no conhecimento e domínio das diferentes tecnologias e recursos midiáticos e sim na compreensão das relações estabelecidas pelos alunos na aquisição do conhecimento: através da interação, eles estabelecem ligações entre ideias, formas de agir e de chegar a determinados objetivos, o que requer mudança no processo de ensino de um para muitos para um em que todos aprendem com todos, a partir da reflexão e apoio comuns. 
A pesquisa aqui descrita é um recorte de uma dissertação de mestrado em educação que utilizou o Facebook como ambiente de aprendizagem para o desenvolvimento de uma proposta participativa, nos moldes do que propõe a Educação 3.0.

Os sujeitos da pesquisa são os dezessete estudantes da disciplina Português Instrumental do curso de Letras Vernáculas da Universidade Federal de Sergipe.

O método de abordagem da pesquisa estabelecido foi o da Pesquisa-formação, que, conforme Longarezi e Silva (2008, p. 4.056), caracteriza-se como uma forma de se fazer ciência em que "o pesquisador sai da clausura de seu laboratório e vai atrás dos problemas do professorado, trabalhando com ele para a solução desses mesmos problemas de forma conjunta e cooperativa". Trata-se de um modelo em que o pesquisador não é neutro, mas que reconhece as inúmeras relações envolvidas na escola, enquanto local de realização da prática docente e o professor enquanto sujeito de sua prática. A delimitação por este método deu-se pela implicação natural do pesquisador com o campo pesquisado, em que se tem a possibilidade de construir com os sujeitos conhecimentos e métodos outros, onde pesquisador também é sujeito, envolvido na reflexão acerca de sua própria prática, o que implica no redimensionamento do papel docente e na formação de um professor crítico, autônomo, que pesquisa a sua própria prática (LONGAREZI; SILVA, 2008). Assim, a pesquisa está articulada com o fazer do professor e ao espaço escolar e pressupõe mudanças das práticas e dos sujeitos em formação. Ele é ao mesmo tempo objeto e sujeito da formação (NÓVOA, 2004).

Utilizou-se como instrumentos de pesquisa a observação participante em sala de aula e no grupo criado para a disciplina no Facebook, um questionário com perguntas abertas e fechadas, aplicados ao final do curso e, a fim de avaliar a proposta sob o olhar dos futuros docentes, realizou-se uma entrevista semiestruturada direcionada apenas aos alunos licenciandos da turma. Para garantir a privacidade dos envolvidos, optou-se por nomeá-los pelos nomes das letras do alfabeto grego. A pesquisa não foi submetida ao Comitê de Ética da instituição, todavia, buscou-se seguir os princípios mediante concordância e assinatura dos participantes no Termo de Consentimento Livre e Esclarecido. Todas as entrevistas foram gravadas e transcritas manualmente a fim de se proceder à análise e, uma vez transcritas, elas foram reenviadas aos participantes para sua análise e concordância e/ou possíveis ajustes.

Dada a natureza da pesquisa, na área de formação de educadores, bem como de todo o processo que a norteia, de ordem da praxis pedagógica, buscou-se aprofundar, através da entrevista semiestruturada, questões relacionadas à formação docente e uso das TDIC, à visão do futuro docente sobre a associação entre os diversos recursos e conteúdos disponíveis na Internet para fins pedagógicos, dentre outras que serão descritas na seção que trata da prática desenvolvida. 
O olhar do futuro docente constitui-se como foco principal nessa abordagem, bem como a interação entre aluno-aluno e aluno-professor e as relações existentes entre o saber que se faz no ambiente formal de estudo e em ambientes informais. A intenção é "aproximar pesquisa e educação como processos formativos que permitem o desenvolvimento dos sujeitos envolvidos (pesquisadores, professores, estudantes, entre outros)”, conforme Longarezi e Silva (2013, p. 217).

Neste artigo, recortamos a categoria que trata do uso de recursos e propostas que evidenciem o uso das TDIC no processo de encaminhamento para uma Educação 3.0. Assim, buscou-se saber como os licenciandos enxergam essa mudança de foco no processo de ensino e quais as situações de aprendizagem vivenciadas por eles em sua formação inicial. Para Alfa, a universidade tem uma diversidade de práticas e de professores e, muitas vezes, "a teoria e a prática é um pouco distante e o que a gente aprende aqui muitas vezes não vai colocar em prática na sala de aula”.

Ainda a universidade está muito presa não à prática e mais à teoria e isso dificulta porque a gente tem muitos alunos que eles são mais elétricos e aprendem mais na prática do que na teoria. Um dos maiores problemas da universidade é esse [...] (ÔMICRON).

Eu vim de escola pública e não tenho base. Estou no ensino superior mas sem base nenhuma do ensino básico. Os professores não eram muito presentes, não ensinavam com novos métodos, não tinha aquela dinâmica com a turma. Ele chegava, passava o conteúdo e alguns nem explicavam direito. Uma vez, aconteceu de uma aluna ter uma dúvida e a professora não soube nem explicar em sala. Como eu sabia o conteúdo eu expliquei pra garota (OMEGA).

Os depoimentos ressaltam uma realidade que não está limitada a determinado nível de ensino: quer na educação básica, quer no ensino superior, existem situações em que a prática docente não atende ao que o aluno espera da escola: uma aprendizagem que equilibre teoria e prática em seu processo. Porém, considerando a formação de futuros docentes, é um paradoxo que a prática esteja distante da realidade, afinal, como prepará-los para o exercício da docência (o que implica prática), sem oferecer subsídios para essa base? Considerar o processo dialógico que perpassa a relação professor-aluno é fundamental para o sucesso da prática docente.

Em relação às teorias de aprendizagem relacionadas ao objeto desta pesquisa e discutidas neste trabalho, a colaboração foi apresentada como a principal destas, tendo como base a teoria vygotskyana. Falar de aprendizagem em um cenário de mudanças e inovações, afirmam Nunes e Nunes (2012), é utilizar a concepção de Vygotsky, que pressupõe "um processo dialético no qual o aprendiz é um sujeito ativo, concreto, histórico, em permanente transformação e diálogo com o mundo" (idem, p. 127).

Por colaboração, entende-se a aprendizagem que ocorre e se desenvolve a partir da interação entre os indivíduos movida pelas experiências partilhadas na construção do conhecimento, que levam 
à aquisição de novos saberes a partir daqueles que os geraram. Para Palloff e Pratt (2004), onde quer que ocorra, quer em ambientes online, quer em sala de aula presencial, a atividade colaborativa é o cerne do curso centrado no aluno e pode ser observada quando ele passa também a refletir sobre a aplicação à sua vida de algo que aprendeu ou sobre o significado de alguma coisa que leu nesses ambientes.

Buscando verificar, mediante o questionário aplicado, a percepção da turma quanto ao processo de colaboração entre eles, $85 \%$ afirmou que houve colaboração entre os participantes, ocorridas da seguinte forma: $70 \%$ no desenvolvimento de atividades; $54 \%$ no esclarecimento de dúvidas e $46 \%$ na troca de experiências de estudo. Os dados foram obtidos mediante o questionário, porém sentiu-se necessidade de aprofundar essa questão através da entrevista, dada a importância da compreensão sobre aprendizagem colaborativa como teoria de aprendizagem em rede. Os depoimentos dos licenciandos confirmam as situações de colaboração apontadas, relacionadas às trocas de experiências, esclarecimento de dúvidas e desenvolvimento de atividades:

Foi uma forma a mais de discussão, de aprendizagem e troca de informação, que às vezes pela internet dá um pouco mais de coragem de falar, de abrir uma discussão, foi importante. Eu fazia muitos comentários, havia muitas discussões, eu gostava mesmo de ver o que o colega estava vendo, se eu estava vendo de uma forma errada. [...] eu aprendo muito mais com erro que com acertos, porque o erro fica persistindo na cabeça da gente...ah, eu deveria ter feito de outra forma (ÉPSILON).

A gente postava atividade, os colegas criticavam ou não as atividades. Eles poderiam também dizer se estava correto, se não estava, teve interação um com o outro... Eu aprendi alguma coisa também. Teve erros, teve acertos, tinha coisas que eu não sabia, que eu aprendi com os colegas [...] (OMEGA).

Eu pude ter acesso ao que você fala, o que você fala eu também quero saber, porque às vezes isso influencia no que eu formular. Então isso é essencial, porque às vezes, no caso de uma prova, de uma atividade, o professor pega e só tem acesso pra ele. A gente fica curioso em saber o que ele escreveu, a gente não tem acesso. [...] Então acho que se a gente criar algo pra ser exposto, você tem que saber o que vai falar, pra não jogar qualquer coisa. Isso influencia num cuidado maior, com certeza, [...] não tem como, porque você fica preocupado e isso é fundamental, porque sabe que tem algo a melhorar (ÔMICRON).

Para Palloff e Pratt (2004), pedir que os alunos respondam às questões de discussão e mensagens de seus colegas é o primeiro passo para dar início ao processo de reflexão. Confirmando o que os depoimentos apresentam, os autores destacam o valor da aprendizagem online ao permitir que os alunos tenham tempo de refletir sobre o material que estudam e sobre as ideias de seus colegas, antes de escreverem suas respostas. Esse processo faz com que eles percebam que a aprendizagem não ocorre somente pela interação com o professor, mas que é importante saber o que o outro tem a dizer, como o outro enxerga determinada situação, como realiza suas tarefas. 
De acordo com a percepção de Gallana (2013), colaboração é uma ação educativa em que os sujeitos constroem o seu conhecimento a partir de discussões e reflexões sobre determinado assunto, sob a mediação de computadores e outras tecnologias de comunicação ou não. Assim, considera-se que houve, de fato, colaboração no desenvolvimento da proposta, pois novos conhecimentos foram gerados entre os indivíduos a partir do contato com o conhecimento do outro. Porém, colaboração não se resume a tais situações, ela vai além da simples troca de informação e precisa promover parcerias entre todos na busca por resultados que não poderiam ser alcançados por indivíduos isolados.

Assim, buscou-se algum indício de atividades que tenham atendido a esse princípio, que tenham promovido parcerias entre os estudantes na busca por objetivos comuns. Destacam-se, nesse quesito, as atividades realizadas em grupo para a realização de seminários. Como os alunos eram oriundos de cursos e turnos diversos, a saída encontrada por eles foi estabelecer o Facebook como local de articulação e distribuição de tarefas. Sobre esta experiência, os licenciandos discorrem que:

Geralmente, os trabalhos em grupo foram tranquilos. Dividíamos os assuntos, discutíamos alguma coisa. Geralmente a gente se organizava na biblioteca, num curto espaço de tempo. Mas na rede social mesmo é que a gente conversava mais. Houve divisão de trabalho, a gente discutia bastante $\circ$ assunto, trocava informação (ÉPSILON).

Foi bem tranquilo, porque como muitas vezes nem todos os alunos tinham esse tempo pra se reunir e quando tinha trabalho em grupo, em dupla, cada um tinha a sua parte, nós juntávamos e todos liam o material inteiro e eu desenvolvia a questão dos exercícios individuais. Como sempre tinha uma data limite, geralmente eu respondia à noite, bem tranquilo, tinha à mão livros, o google, fora as aulas que estavam postadas também. Eu interagia bem com os colegas, a gente se comunicava pelo Face mesmo, em relação ao que cada um ia falar, revisão do trabalho, o que cada um ia fazer. Acredito que não pesou, não ficou sobrecarregado pra ninguém, porque foi tudo dividido, um escrevia, passava para o outro (ALFA).

Observa-se que os alunos conseguiram estabelecer uma relação harmoniosa para a resolução de um objetivo comum: conciliar os horários entre os integrantes dos grupos e desenvolver uma boa apresentação, utilizando o espaço de aprendizagem para esse fim, estabelecendo as mesmas relações em equipe no ambiente online que poderiam ser desenvolvidas presencialmente. Através da utilização da plataforma, foi possível desenvolver atividades onde todos participaram, através da exploração de seus diversos recursos, onde os alunos compartilharam não apenas informações e arquivos, mas dúvidas, anseios e sucessos, graças às possiblidades de conexão em rede.

Acerca do conectivismo, proposto na pesquisa de que este trabalho se origina, em parceria com a teoria de aprendizagem colaborativa, compreende-se que a aprendizagem deve ir além do domínio formal, pois diz respeito à abundância de recursos e informações disponíveis na web, 
presentes em todas as áreas da vida e que podem ocorrer a partir das conexões entre informações, conceitos e saberes.

Nesse sentido, não basta se limitar ao conhecimento e informações disponibilizadas pelo livro didático. O professor precisa apresentar e avaliar mais do que o conhecimento que os alunos têm do conteúdo por ele ensinado, como defendem Palloff e Pratt (2004, p. I I I). É importante usar a "matéria estudada para ensinar os alunos a pensar e desenvolver habilidades cognitivas mais elevadas", tais como analisar argumentos, compreender informações de diferentes fontes, resolver problemas e aplicar o que aprenderam a diferentes contextos.

Eles evidenciam em seus depoimentos os anseios por uma formação cuja base metodológica explore as TDIC, para que a experiência obtida nessa fase seja capaz de prepará-los eficazmente para o exercício da prática, compreendendo-se que as dificuldades precisam ser enfrentadas na formação inicial, para que se estabeleçam estratégias e reflexões sobre ações futuras e assim se evite a sensação de inaptidão para prosseguir na profissão com qualidade.

Intencionando saber como os licenciandos avaliam uma prática que vá além do livro didático, que considere as informações e conhecimentos distribuídos na web, na perspectiva conectivista, obtiveram-se os seguintes depoimentos:

Eu acredito que todos os recursos são válidos, desde que venham contribuir com o conhecimento, são válidos. É importante usar todos os recursos, desde a própria televisão, cinema, filmes, todos os recursos podem ajudar, até porque na sociedade atual, com a velocidade, a rapidez, atrair o aluno é complicado, Ficar só falando e falando não ajuda. Tem que trazer muitos recursos. Há muitos vídeos que retratam artistas, vida e obra. É importante trazer isso, como a televisão, que pode discutir ou ver um programa, um documentário, que podem informar o aluno (ÉPSILON).

Tecnologias motivam bem, porque o aprendizado do inglês está ali. Fonética vc baixa - aplicativo tem lá, fonética do inglês, ele já dá a pronúncia perfeita, então tecnologia está essencial. Não sei porque não usam... $\bigcirc$ que barra em dizer que a educação não está mais além, porque tem muitos professores ainda que são mais antigos, eles não sabem muito sobre a tecnologia de hoje, aí barra o aluno ali, não leva além (ÔMICRON).

O uso da internet no ensino nos dias atuais não está adequado. Os livros seriam ideais, porque a internet tem conteúdos, mas não são fontes seguras. Nem todas, algumas, sim. Site de professores, doutores, eles escrevem seus artigos e publicam. Já é uma ajuda para os estudantes. Eu creio que ajude, mas a utilização dos livros ainda seria mais adequada (OMEGA).

Nesse questionamento, destaca-se o depoimento muito pertinente de Épsilon, que não restringe o uso de recursos e conteúdos didáticos àqueles veiculados na web, mas aponta o uso de mídias de massa, como a televisão, o cinema e os vídeos elaborados especificamente para uso escolar, como estratégia de atrair a atenção do aluno. 
No depoimento de Ômicron, tem-se uma sugestão muito interessante acerca do uso de aplicativos para ensino e treino fonético da língua inglesa, que podem ser baixados em celulares e smartphones e trabalhados em sala. O licenciando questiona-se por que os demais professores não fazem uso deles, já que são tão acessíveis, apresentando, ele mesmo, a resposta: professores mais antigos não sabem muito sobre a tecnologia. Seria uma tendência relacionada à idade? Um típico caso de indivíduos imigrantes digitais, nascidos antes da disseminação das TDIC? O licenciando responde: "Acho que a idade não influencia nisso, acho que é formação. Tem professor que chegou ali parou, não dá continuidade a outra coisa, não faz um curso diferente..."

Sobre as gerações e sua relação com as tecnologias, ressalta-se que esta divisão não é especificamente cronológica; é possível haver indivíduos que só tiveram contato com as tecnologias digitais em fase posterior à sua existência perfeitamente adaptados a elas, enquanto outros, considerados nativos digitais por nascerem num período em que a internet já estava em pleno avanço, não sabem lidar com os recursos e funcionalidades ou simplesmente não gostam ou ainda não têm acesso a estes.

Um exemplo de casos assim fica evidente no posicionamento de Omega quanto ao uso de softwares e plataformas de redes sociais da internet em situações de aprendizagem: em seu depoimento acerca da prática conectivista, a licencianda defende o livro como recurso fundamental, já que a internet não é "muito confiável" e seu uso "no ensino nos dias atuais não está adequado". Procurou-se aprofundar este pensamento da aluna, confirmando se, para ela, na sala de aula basta que o professor use o livro didático como única fonte de informação e conhecimento, ao que se obteve como resposta: "Só o livro? Bom, tem que trazer outras fontes também, não só o livro, como artigos, que são interessantes, tem que ser uma fonte segura, porque nem todas são. Outras também são importantes".

É importante considerar a posição da aluna, uma vez que questões de validade e credibilidade das informações que circulam na internet devem ser discutidas no processo, mas percebe-se que, apesar de nascida na esteira da geração digital, a aluna não é adepta de recursos e softwares disponíveis na internet, o que reafirma $\circ$ que se colocou, de que as divisões apontadas por Tapscott não são cronológicas e que indivíduos podem se identificar com perfis diversos de sua geração. $O$ respeito aos limites e possibilidades individuais é fundamental para que a prática ocorra de forma a atender às necessidades do grupo. Sendo assim, é preciso atenção às dinâmicas dos grupos, à diversificação de atividades propostas e ao diálogo constante, a fim de estabelecer um ambiente em que a participação de todos ocorra de forma harmoniosa.

A prática desenvolvida com a turma de Português Instrumental, fundamentada na Pesquisaformação, demonstra seu uso como um ambiente utilizado em concomitância com a disciplina 
presencial em todo o curso, não apenas em uma atividade ou proposta ou projeto isolados. Os dados apresentados evidenciam resultados satisfatórios desse uso, pois foi possível empreender discussões síncronas e assíncronas entre estudantes entre si e entre estes e a docente, propor e realizar atividades diversas, acompanhar o processo de realização das tarefas e a participação dos alunos, estabelecer comunicação mediante avisos e prazos, postar recursos sob diversos formatos (vídeo, imagem, texto), tudo dentro de um grupo fechado, com diretrizes estabelecidas previamente e privacidade. A ampliação do espaço de aprendizagem, citado pelos alunos da disciplina, foi o grande diferencial da proposta, permitindo dar continuidade às discussões promovidas em sala e ao aluno a opção de desenvolver suas atividades em horários condizentes com seu tempo disponível.

Verificou-se, com essa estratégia, uma parceria em que as relações entre alunos e professor se equilibram, descentralizam-se, onde ação e reflexão caminham juntas, compondo as experiências que fundamentarão práticas futuras. Com isso, julga-se que a pesquisa alcançou o que Santos e Blázquez (2006) afirmam: quando o professor reflete sobre sua prática com a intenção de promover uma aprendizagem autônoma, ele está dando voz ao sujeito em formação e, assim, restituindo ao professor e ao aluno sua identidade e responsabilidade perdidas e à universidade sua condição de lugar onde interação e aprendizagem caminham juntas. Afinal, como afirma André (1995, p. II5), "se queremos formar um professor que seja sujeito consciente, crítico, atuante e tecnicamente competente é preciso dar condições, na sua formação, para que ele vivencie situações que o levem a incorporar essas habilidades e esses comportamentos".

Os depoimentos dos licenciandos, em sua maioria, ressaltam esse saber construído em conjunto e compartilhado, que promoveu maior cuidado com a produção e recepção do texto, como também pela oportunidade de saber o que o outro diz, por que ele diz e as razões que fundamentam seu pensamento.

\section{Considerações finais}

A aprendizagem que se faz no contexto da Educação 3.0 é um processo contínuo, pois os alunos pesquisam e criam soluções e apresentações, acessam os materiais disponibilizados pelo professor (atividades ou conteúdos didáticos), apresentados e discutidos em sala de aula, como forma de apoio e reforço. Dessa forma, otimiza-se o tempo de aula, utilizando-o para lidar com os problemas mais complexos.

Para inserir eficazmente as novas práticas de ensino para a Educação 3.0, é preciso adotar novos paradigmas, baseados nas necessidades de aprendizagem do aluno; o principal é que o professor saiba se comunicar utilizando todos os meios possíveis (oral, gestual, virtual, digital, etc.) e que utilize uma linguagem atualizada, o que se resume em sua capacidade de adaptação ao público-alvo. Em suma, 
o professor precisa também estar conectado: com o aluno, com sua forma de enxergar o mundo e o conhecimento, com as mudanças comunicacionais, com as mais recentes ferramentas digitais.

A intencionalidade é uma dimensão normativa da prática educativa e isso implica em objetivos, em sobre para quem e por que se educa e quais meios para isso. O ato de educar é, dessa forma, norteador da prática docente. Se é preciso repensar a escola e o papel que ela exerce diante de uma sociedade cada vez mais informatizada, em que a comunicação e interação entre os indivíduos se faz sob formatos tão variados e a cada dia de forma mais online que tradicionalmente face a face, é urgente repensar o papel docente e seus processos formativos. Para isso, é preciso estabelecer metodologias que motivem no estudante o esforço necessário para que a aprendizagem ocorra, o que pode acontecer a partir da elaboração de atividades de aprendizagem que se estendam além da sala de aula.

Toda prática deve pressupor objetivos, planejamento e intervenção para uma aprendizagem eficaz. A concepção de ensino sob essa ótica perpassa tanto a formação de professores como o ensino, o currículo e a metodologia. Imbernón (2006) fortalece esta discussão quando reafirma o papel da formação que vá além do ensino como atualização pedagógica e didática, configurando-se como possibilidade de criação, espaço de reflexões e participações, onde se aprende e se adapta para a convivência, para a mudança e a incerteza.

A formação cidadã é um dos principais objetivos educacionais e uma educação de qualidade deve estabelecer por objetivos: a preparação para o mundo do trabalho, proporcionando a formação geral necessária para que os futuros trabalhadores possam assumir a complexidade do exercício profissional, articulando conhecimento, ação e valores, dentro da cultura tecnológica; oferecer formação para a cidadania crítica, em que o cidadão-trabalhador seja capaz de interferir criticamente na realidade a fim de transformá-la; preparação para a participação social, através do desenvolvimento de competências sociais, como atividades em grupo, tomada de decisões de forma democrática, capacidade de iniciativa, liderança, solução de problemas, etc.; formação ética, fundamental para formar valores e atitudes ante o mundo em relação à política e da economia, ante o consumismo, o sexo, a droga, a preservação ambiental, a violência e a todas as formas de exploração típicas do capitalismo.

Em seus depoimentos, os futuros docentes refletiram sobre as práticas vivenciadas ao longo de sua educação básica e, principalmente, sobre sua formação inicial, destacando a ausência de uso das tecnologias, de práticas mais dinâmicas, de metodologias eficientes, o que culmina em insegurança em relação aos desafios futuros. Se o estudante deve ser preparado, independentemente dos destinos profissionais escolhidos, levando-se em consideração sua formação cidadã e o exercício profissional, é preciso então atrelar o ensino às práticas que se fazem na sociedade informatizada e interconectada em que vivemos. 
Como propostas de pesquisas futuras, e diante do contexto atual, consideramos a pertinência de se atrelar, nos cursos de formação inicial, práticas que explicitem como se apropriar das ferramentas de forma pedagógica, selecionando e aliando os conteúdos formais necessários à formação do aluno às mais atuais formas de aquisição do conhecimento, considerando os perfis docentes necessários à educação do tempo presente.

Com o futuro da prática docente tal qual conhecemos e vivenciamos por tantas décadas tão incerto, esta pesquisa leva-nos a questionar qual o futuro das práticas e didáticas de formação de professores e que caminhos precisam ser tomados para uma formação que vise promover o processo de aprendizagem, seja por meio do ensino presencial ou não.

\section{Referências}

ALLAN, L. M. Educação 3.0: estamos prontos? Editora Abril: Educar para crescer. Publicação online,s/p., 08 ago. 2012. Disponível em: https://www.pautaonline.com.br/blog/educacao-30-estamosprontos/93. Acesso em: 02 mar 2014.

ANDRÉ, M. E. D. A. Etnografia da prática escolar. Campinas: Papirus, 1995.

FAVA, R. Educação 3.0: como ensinar estudantes com culturas tão diferentes. $2^{\mathrm{a}}$ Ed. Cuiabá: Carlini e Caniato Editorial, 20II.

GALLANA, L. M. R. Facebook: um espaço de colaboração para a troca de experiências com uso de tecnologias em sala de aula. 2013. Dissertação (Mestrado em Educação) - Universidade Estadual de Campinas, São Paulo, 2013. Disponível em:

http://repositorio.unicamp.br/jspui/handle/REPOSIP/250857. Acesso em: I3 mar 20 I4.

IMBERNÓN, F. Formação docente e profissional: formar-se para a mudança e a incerteza. $6^{a}$ ed. São Paulo: Cortez, 2006.

LENGEL, J. Educação 3.0. Estadão, on-line, 07 nov. 20I2. Caderno Educação. Disponível em: http://educacao.estadao.com.br/noticias/geral,artigo-educacao-30,956582. Acesso em I4 jul. 2014.

LIBÂNEO, J. C. Adeus professor, adeus professora?: novas exigências educacionais e profissão docente. São Paulo: Cortez, 201 I.

LONGAREZI, A. M.; SILVA, J. L. Pesquisa-formação: Um olhar para sua constituição conceitual e política. Revista Contrapontos, v. 13, n. 3, p. 214-225, set./dez., 2013. Disponível em:

https://siaiap32.univali.br/seer/index.php/rc/article/view/4390. Acesso em: 20 fev. 2015.

LONGAREZI, A. M.; SILVA, J. L. Interface entre pesquisa e formação de professores: delimitando o conceito de pesquisa-formação. In: VIII Congresso Nacional de Educação - EDUCERE, 2008, Curitiba. Anais [...] Curitiba, Paraná, 2008. Disponível em: https://educere.pucpr.br/p8/anais.html. Acesso em: 13 dez 2014.

NÓVOA, A. Prefácio. In: JOSSO, M.C. Experiências de vida e formação. São Paulo: Cortez Editora, 2004. Página 7-12. 
NUNES, J. B. C.; NUNES, A. I. B. L. Formação De professores na era de tecnologias digitais: desafios para a educação neste milênio. In: SCHNEIDER, H. N.; LACKS, S. (org.). Educação no século XXI: desafios e perspectivas. São Cristóvão: Editora UFS, 2012. Página II7- 144.

PALLOFF, R. M.; PRATT, K. O aluno virtual: um guia para trabalhar com estudantes on-line. Trad. Vinícius Figueira. Porto Alegre: Artmed, 2004.

PRENSKY, M.: Digital Natives Digital Immigrants. In: PRENSKY, Marc. On the Horizon. NCB University Press, v.9, n.5, oct., 200I. Disponível em:

http://www.marcprensky.com/writing/Prensky\%20-

\%20Digital\%20Natives,\%20Digital\%20Immigrants\%20-\%20PartI.pdf. Acesso em I3 dez 2014.

SANTAELLA, L. Culturas e artes do pós-humano: da cultura das mídias à cibercultura. São Paulo: Paulus, 2003.

SANTOS, I. P.; BLÁZQUEZ, F. Incorporação das novas tecnologias no ensino superior. Goiânia: R\&F, 2005.

SOUZA, A. A. N. O Facebook como ambiente de aprendizagem: uma análise da praxis presencial mediada pelo conectivismo pedagógico. 2015. 187 f. Dissertação (Mestrado em Educação) Universidade Federal de Sergipe, São Cristóvão, 2015.

STAHL, M. M. Formação de professores para uso das novas tecnologias de comunicação e informação. In: CANDAU, Vera Maria (org.). Magistério: construção cotidiana. Petrópolis, RJ: Vozes, 1997, p. 292-317.

TAPSCOTT, D. A hora da geração digital: como os jovens que cresceram usando a internet estão mudando tudo, das empresas ao governo. Trad. Marcello Lino. Rio de Janeiro: Agir negócios, 2010.

VYGOTSKY, L. S. Pensamento e Linguagem. $4^{\text {a }}$ ed. São Paulo: Martins Fontes, 2008.

Recebido em: 04 de março de 2021 .

Versão corrigida recebida em: 25 de maio de 202I.

Aceito em: 26 de maio de 2021 .

Publicado online em: 25 de fevereiro de 2022

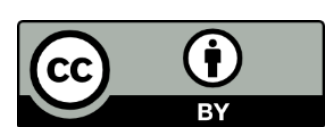

